\title{
Preprosthetic Orthodontic Treatment of Deep Bite with Congenitally Missing Mandibular Central Incisors
}

\section{Vanashree Takane*}

Department of Orthodontics and Dentofacial Orthopaedics, Smilekart Dental Clinic Atria, Brahmand, Thane west, Maharashtra, India

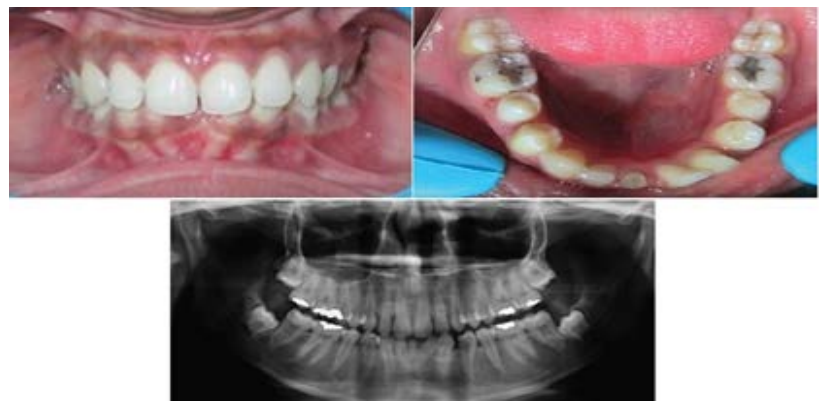

Figure 1: Pretreatment images.

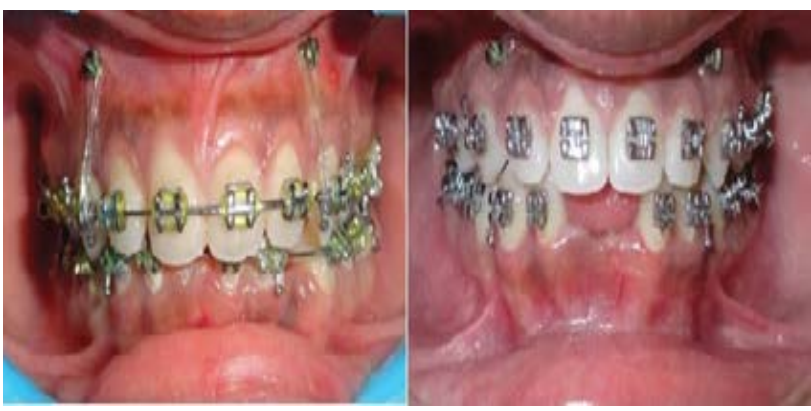

Figure 2: Intrusion with implants.

Keywords: Preprosthetic; Dental; Orthodontic

\section{Case History}

The objective of a preprosthetic orthodontic treatment is to position the teeth in such a way that a treatment with (fixed) dental prostheses is made possible or simplified or to affect the result of this treatment positively. For deep bite cases with agenesis and/or early loss of teeth, a treatment with either fixed dental prostheses is usually indicated after correction of anterior deep bite. This helps to achieve sufficient clearance for fabrication of fixed prosthesis. This is a case report of an 18-year-old female patient referred for preprosthetic orthodontic treatment. She had Class I malocclusion with deep bite and congenitally missing mandibular central incisors (Figure 1). Bonding of both arches was done with 022 MBT bracket systems. In this case intrusion of maxillary anterior teeth was achieved with mini screw implants $(1.2 \times 6 \mathrm{~mm})$ placed between lateral incisors and canines bilaterally for 7 months.

Open niti coil spring on $19 \times 25$ SS was placed to restore the space for the missing incisors in lower arch Case was debonded once sufficient clearance was achieved for the fabrication of prosthesis. Total treatment time was 12 months (Figures 2 and 3 ). Correction of deep bite with $5 \mathrm{~mm}$ of true intrusion was achieved and the FPD was bonded successfully.

*Corresponding author: Vanashree Takane, Department of Orthodontics and Dentofacial Orthopaedics, Smilekart Dental Clinic Atria, Brahmand, Thane west, Maharashtra, India, Tel: +91-9860566883; E-mail: vanashree3087@gmail.com

Citation: Takane V (2019) Preprosthetic Orthodontic Treatment of Deep Bite with Congenitally Missing Mandibular Central Incisors. Int J Clin Med Imaging 6: 634. doi: $10.4172 / 2376-0249.1000634$

Copyright: (C) 2019 Takane V. This is an open-access article distributed under the terms of the Creative Commons Attribution License, which permits unrestricted use, distribution, and reproduction in any medium, provided the original author and source are credited. 